\section{Professor Hamm wird mit der H. R. Schinz-Medaille geehrt}

Am 20. Mai wurde im Rahmen des Schweizerischen Röntgenkongresses Herrn Prof. Dr. Bernd Hamm, Direktor der Klinik für Radiologie der Berliner Charité, die H. R. Schinz-Medaille verliehen. Bereits seit 2009 ist Professor Hamm Ehrenmitglied der Schweizerischen Gesellschaft für Radiologie. Mit der jetzt verliehenen Auszeichnung wurde insbesondere sein engagierter Einsatz für die Entwicklung der diagnostischen Radiologie gewürdigt. In seinem Festvortrag unterstrich Professor

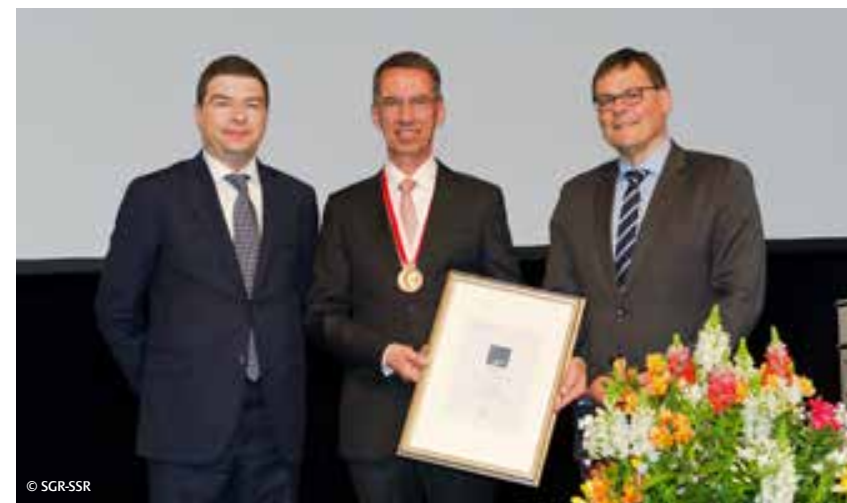

Hamm die zentrale Rolle der parametrischen MRT für die frühe Erkennung des Prostatakarzinoms, für die er auf eine spezielle Expertise verweisen kann.

Die H. R. Schinz-Medaille wurde 1983 in Erinnerung an Professor Dr. med. Dr. h.c. Hans Rudolf Schinz (1891-1966) geschaffen. Prof. Schinz war Ordinarius für Radiologie und Direktor des Röntgenzentralinstitutes für Diagnostik und Therapie des Kantonsspitals Zürich (heutiges Universi-

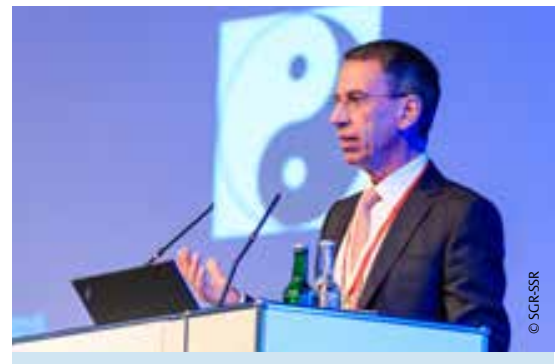

Prof. Dr. Bernd Hamm

tätsspital Zürich). Er gilt als Pionier der Radiologie mit großer nationaler und internationaler Ausstrahlung. Sein Name ist verbunden mit einem der ersten umfassenden Lehrbücher der Radiologie, welches über Jahre den Stand des Wissens in der Radiologie repräsentierte und als Standardwerk galt.

Die H.R. Schinz-Medaille ist die höchste von der SGR-SSR verliehene Auszeichnung. Sie wird alljährlich anlässlich der H.R. Schinz-Vorlesung im Rahmen des Jahreskongresses durch den Präsidenten der SGR-SSR an nationale und internationale Persönlichkeiten verliehen, welche sich auf dem Gebiet der Radiologie besondere Verdienste erworben haben.

PD Dr. med. Kay-Geert Hermann 